\title{
Mycosis fungoides and gastric T-cell lymphoma: A case report
}

\author{
ELISABETTA SCALI ${ }^{1}$, IVAN PRESTA ${ }^{1}$, ANNALIDIA DONATO ${ }^{2}$, GIUSY SCHIPANI ${ }^{1}$, \\ STEFANO DASTOLI $^{1}$, MARCO ROSSI ${ }^{3}$, CHIARA MIGNOGNA ${ }^{4}$, NATALIA MALARA ${ }^{3}$, \\ STEVEN PAUL NISTICO ${ }^{1 *}$ and GIUSEPPE DONATO ${ }^{* *}$
}

\author{
Departments of ${ }^{1}$ Health Sciences, ${ }^{2}$ Medical and Surgical Sciences, ${ }^{3}$ Clinical and Experimental Medicine, \\ and ${ }^{4}$ Interdipartimental Services Center (CIS), University 'Magna Græcia' of Catanzaro, Catanzaro I-88100, Italy
}

Received December 22, 2019; Accepted May 19, 2020

DOI: $10.3892 / \mathrm{mco} .2020 .2085$

\begin{abstract}
Mycosis fungoides (MF) is a cutaneous malignant lymphoma with an extended clinical course. MF presents in series of dermatological manifestations, beginning with patches and plaques of the skin, and eventually evolving into tumours. Often MF can occur for extended periods without worsening of external symptoms, while the disease advances internally in organs such as lymph nodes, liver, spleen, lung, bone marrow, gastrointestinal tract, pancreas and kidney. The present report presents a clinical case in which gastrointestinal symptomatology occurred a decade after the first dermatological manifestation. Immunohistochemical analysis of the skin, along with small bowel biopsies revealed evidence of gastric T-cell lymphoma. To the best of our knowledge, the present study is the first to describe such a case in the literature.
\end{abstract}

\section{Introduction}

Mycosis fungoides (MF) is a cutaneous malignant lymphoma usually with $\mathrm{CD}^{+} \mathrm{T}$ cell phenotype (1) representing almost the $50 \%$ of all primary cutaneous lymphomas and more than $70 \%$ of cutaneous T-cell lymphomas (CTCLs) (2). This disease typically begins affecting the skin with a sequential appearance of patches followed by plaques and has tumors as final outcome. There are several clinical variants of MF including bullous, follicular, granulomatous, pustular, hyperkeratotic, hyperpigmented or hypopigmented, adnexotropic, and purpuriform forms (2). Several authors currently consider Sezary syndrome as an erythrodermic leukemic variant of MF, but in the World Health Organization-European Organization for Research and

Correspondence to: Dr Ivan Presta, Department of Health Sciences, University 'Magna Græcia' of Catanzaro, Viale Europa loc, Catanzaro I-88100, Italy

E-mail: presta@unicz.it

${ }^{*}$ Contributed equally

Key words: mycosis fungoides, cutaneous malignant lymphoma, duodenal T-cell lymphoma, sezary syndrome, prognostic value, transformed mycosis fungoides clinical challenges
Treatment of Cancer (WHO-EORTC) classification of cutaneous lymphomas, it is classified separately as an aggressive form of CTCL (3). In the late stages, MF may have a systemic dissemination with involvement of various organs such us lymph node/peripheral blood, liver, spleen, lung, bone marrow, gastrointestinal tract, pancreas, and kidney. Gastrointestinal (GI) lesions have been reported in some MF patients, although they are mentioned in the literature very rarely (2). In most cases, GI lymphomas are non-Hodgkin type and are commonly characterized by proliferating $\mathrm{B}$ cells while infiltrating $\mathrm{T}$ cells are observed less frequently. T-cell lymphomas are classified into enteropathy associated T-cell lymphoma (EATL), nasal type NK cell lymphoma and other types unassociated with enteropathy (WHO 2018 classification) (4). Few cases of association between GI lymphoma and MF are reported in literature. Mycosis fungoides represents the most frequent CTCL and usually affects middle-aged men (5) with a 2:1 male to female ratio. This malignancy typically involves the skin, mainly in unexposed areas such as trunk, buttocks and thighs (Fig. 1) even if, in the later stages, lymph node and visceral involvement can be observed. The neoplastic infiltrate in MF is mainly represented by $\mathrm{CD}^{+}$cells (Fig. 2 ) that express the T-cell receptor- $\beta$ and are incline to loss the expression of surface markers such as CD2, CD3, CD5, CD7 and CD26 at variable extent. Notably, the loss of CD7 and CD5 is frequently observed in MF and up to $20 \%$ of cases exhibit a CD8 ${ }^{+}$phenotype (6). Clinical and immunophenotypic variants of MF include folliculotropic (follicular mucinosis), bullous, hypopigmented, psoriasiform and palmoplantar forms. The prognostic significance of these variants is still not clear. The prognosis directly correlates with the extent of skin involvement as well as to the presence of extracutaneous disease. Here we present a case of a 65 years old woman, affected by MF who developed a gastric T-cell lymphoma. According to our current knowledge this is the first case described in the scientific literature.

\section{Case report}

A 65 years old woman came along to our observation at Dermatology Department in January 2012, presenting a cutaneous eruption characterized by the occurrence of multiple and extensive inflammatory erythematous patches, slightly scaly. The main diameter of patches ranged, in average, from $2 \mathrm{~cm}$ to more than $10 \mathrm{~cm}$ and lesions were primarily located 
Table I. Antibodies employed for immunohistochemistry.

\begin{tabular}{llll}
\hline Antibody & Source/clonality & Dilution & Company \\
\hline Anti-CD3 & Mouse/monoclonal & $1: 500$ & Leica Biosystem \\
Anti-CD4 & Mouse/monoclonal & $1: 100$ & Leica Biosystems \\
Anti-CD8 & Mouse/monoclonal & $1: 50$ & Leica Biosystems \\
Anti-CD20 & Mouse/monoclonal & $1: 200$ & Dako; Agilent Technologies, Inc.
\end{tabular}
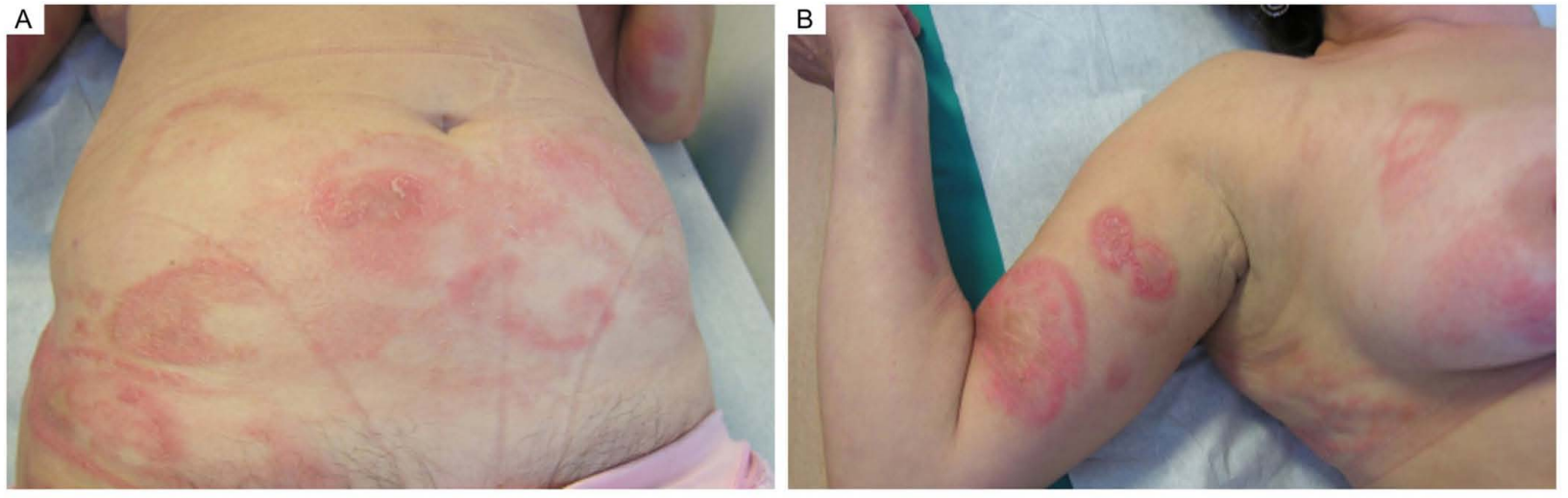

Figure 1. Macroscopic appearance. (A) Typical early patch with erythema and mild scale plaques are presented. (B) Typical plaques with raised, infiltrative and palpable borders, clearing in the center and overlying scale.

on the buttocks, abdomen and legs (Fig. 1). Some lesions had annular appearance with an erythematous and infiltrative border. The patient reported that skin clinical manifestations appeared since ten years before the establishment of a diagnosis of lymphomatoid contact dermatitis. Topical corticosteroid therapy was recommended, but it led to very poor benefit. Because of the referred worsening of cutaneous clinical manifestations, we decided to perform new biopsies of skin lesions and immunohistochemical analysis revealed an epidermotropic lymphocytic infiltrate. The histological and immunohistochemical procedures were carried out according to the previously described methods $(4,7,8)$. The immunohistochemical analyses, performed by using the antibodies listed in Table I, revealed a pattern with simultaneous presence of $\mathrm{CD}^{+}, \mathrm{CD}^{+}$and $\mathrm{CD}^{-}$antigens, confirming the diagnosis of MF (Fig. 2). A topical corticosteroid treatment was prescribed while the patient was undergoing to an attentive follow-up. Due to the appearance of GI symptoms such as gastric pain, an esophagogastroduodenoscopy (EGD) procedure was performed, revealing the presence of an ulcerative nodule into the gastric mucosa. The histological analysis of this tissue revealed a widespread proliferation of lymphoid elements with small and medium size with destruction of gastric glandular structures. Mitotic figures and apoptotic bodies were also evident. The immunohistochemical studies characterized the lymphocytic infiltrates $\mathrm{CD}^{+}, \mathrm{CD} 43^{+}, \mathrm{CD}^{+}$, $\mathrm{CD}^{-}{ }^{-}, \mathrm{CD}^{-} 0^{-} \mathrm{TdT}^{-}, \mathrm{CD}^{-} 9^{-}$. These results were compatible with the histological diagnosis of gastric T-cell lymphoma (Fig. 3). Several cycles of IFN $\alpha$-based therapy were carried out, administered according classic protocols at a dose of $1.5 \mathrm{MU} /$ day s.c. or i.m. during the first week and increased up to $3 \mathrm{MU} /$ day s.c. or i.m. in the second week (9), resulting in clinical benefit and disease stabilization. However, clinical progression of gastric and skin lesions was observed after one year of treatment. Skin lesions further progressed to tumor stage generating large and diffused nodules on the trunk. Patient was hospitalized for planning alternative treatments but clinical conditions rapidly worsened and the patient died within few weeks for metabolic acidosis and multi organ failure.

\section{Discussion}

MF should be differentiated from benign and malignant conditions that report similar clinicopathologic features (10). Several T-cell lymphomas and rarely B-cell lymphomas can display epidermotropic infiltrates, but MF should be also distinguished from various benign inflammatory conditions, including lymphomatoid drug eruptions, lichenoid keratosis, lymphomatoid eczematous dermatitis and the inflammatory stage of lichen sclerosus. Very rarely, other lymphoproliferative disorders such as Castleman's disease or Castleman-like conditions must be considered in the differential diagnosis of $\mathrm{MF}$, especially when multicentric or an anomalous pattern is manifested (11-14). Primary GI lymphomas are not common diseases, occurring more frequently in the 6th decade of age and in males $(15,16)$. There is evidence that tissue resident immune cells, also in CTCLs, have the potential to strongly shape the tissue microenvironment and influence behavior malignant lesions, both participating in many inflammatory and immune reactions or regulating them $(17,18)$. These types of cancers can affect the whole GI tract, particularly stomach and small intestine; esophagus, colon and rectum are involved less frequently. Extracutaneous dissemination is reported in 

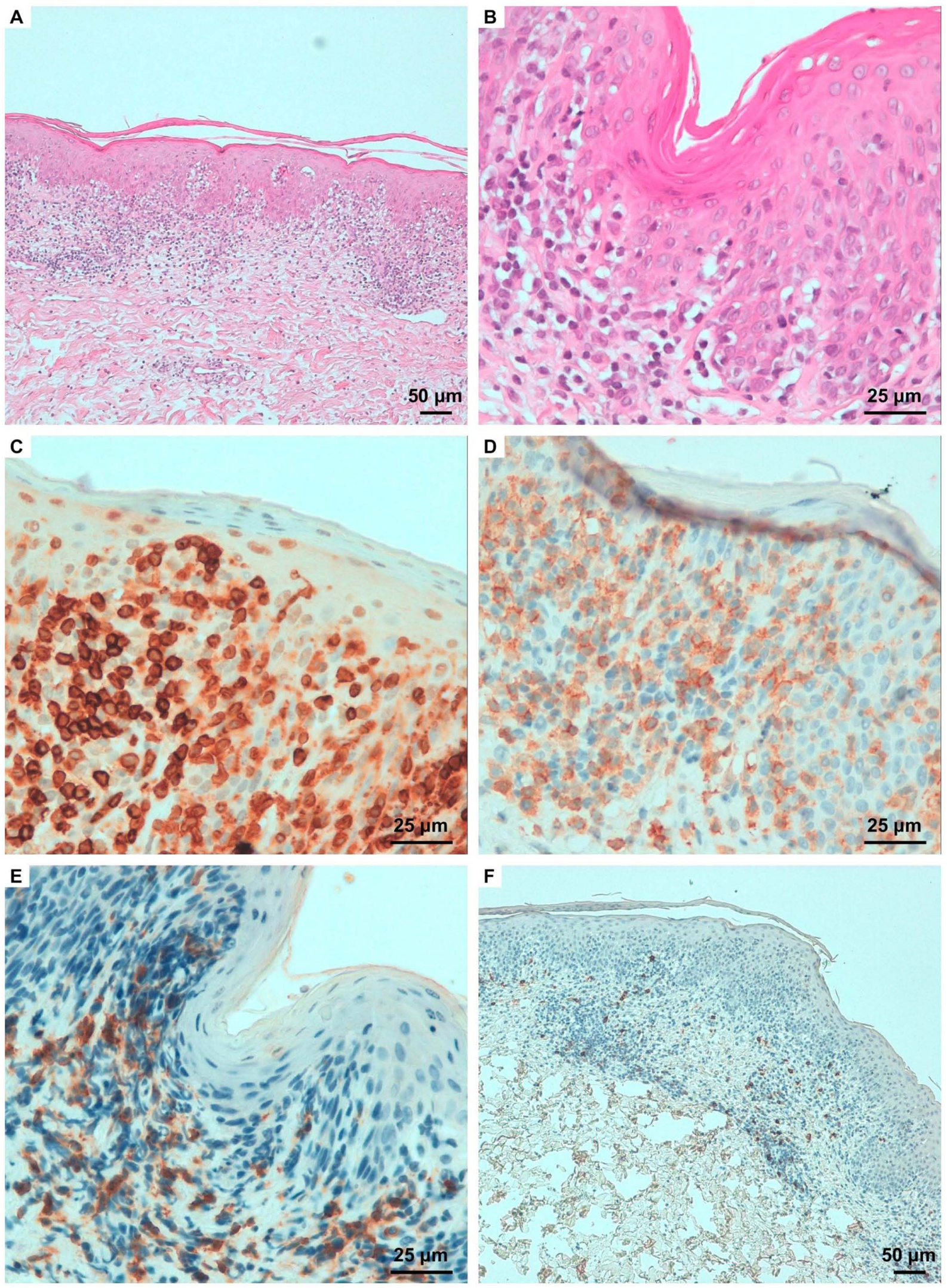

Figure 2. Skin biopsy. Histologic examination of a plaque stage lesion with neoplastic bands of dermal lymphocyte infiltrate. Marked epidermotropism is evident. H\&E staining observed under (A) magnification, $\mathrm{x} 100$ and (B) $\mathrm{x} 400$. Immunophenotype is classically (C) $\mathrm{CD} 3^{+}$(magnification, $\mathrm{x} 400$ ), (D) CD4 ${ }^{+}$ (magnification, $\mathrm{x} 400$ ), (E) $\mathrm{CD}^{-}$(magnification, $\mathrm{x} 400$ ) and (F) CD20- (magnification, $\mathrm{x} 100$ ).

less than $10 \%$ of patients with patch or plaque-accompanied disease and in $30-40 \%$ of patients with tumors or generalized erythrodermatous involvement (3). In early stages, MF could be hardly differentiated from inflammatory cutaneous conditions, even in hands of experienced pathologists. Here because sometimes, this disease may follow its indolent and silent 

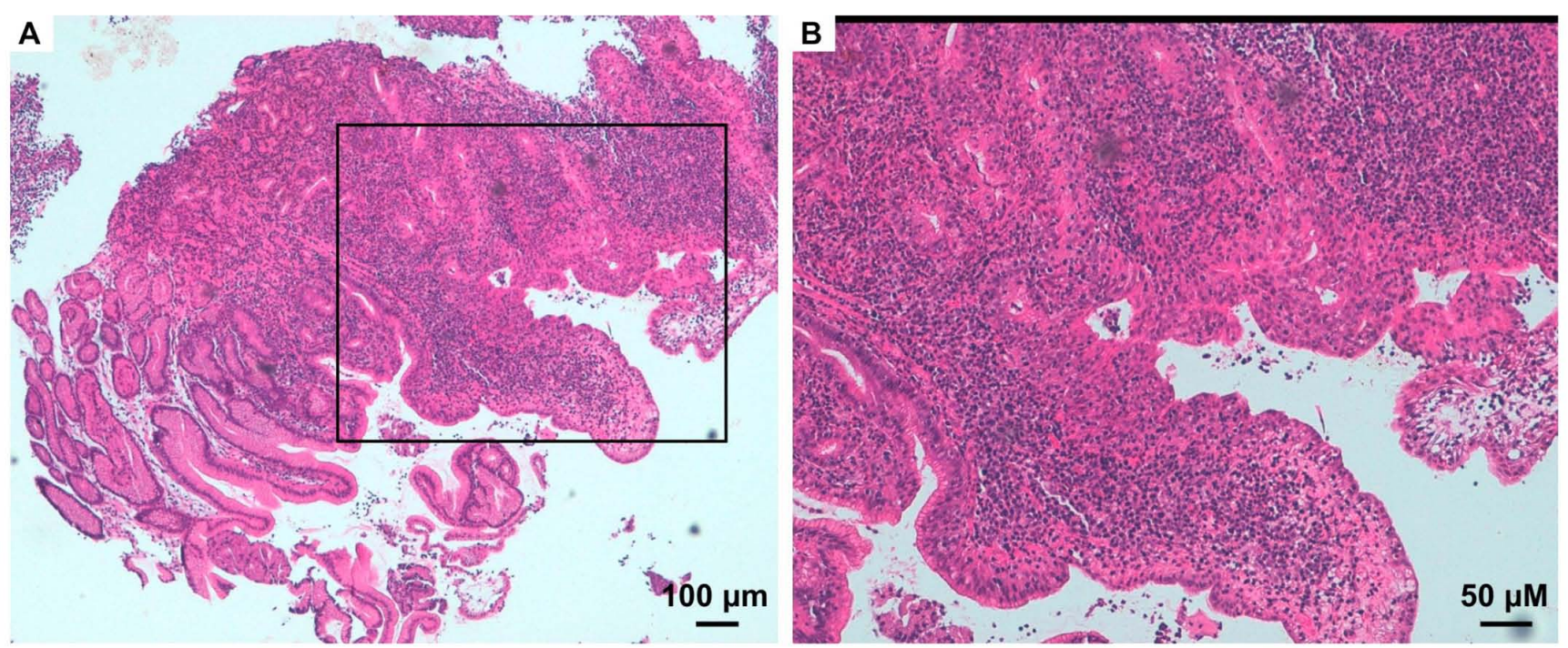

C
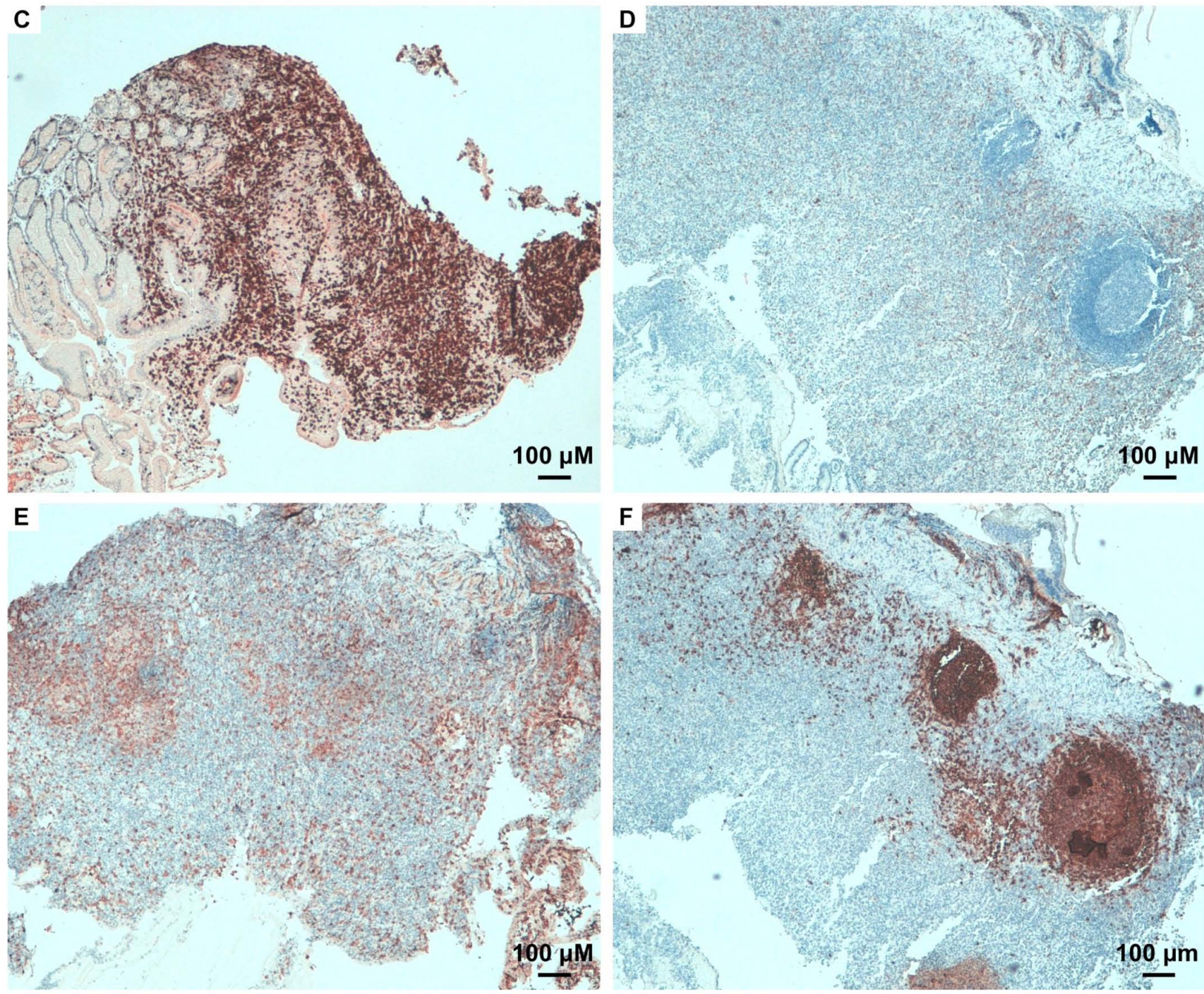

Figure 3. Small bowel biopsy. (A) High degrees of lymphocytic infiltrate is present within the mucosa, as evidenced via H\&E staining (magnification, $\mathrm{x} 40$ ). The framed section in the same panel is magnified in (B) (magnification, $\mathrm{x} 100$ ). Immunophenotype is (C) CD3 ${ }^{+}$(magnification, $\mathrm{x} 40$ ), (D) CD8- (magnification, $\mathrm{x} 40),(\mathrm{E}) \mathrm{CD}^{+}$(magnification, $\left.\mathrm{x} 100\right),(\mathrm{F}) \mathrm{CD} 20^{-}$(magnification, $\left.\mathrm{x} 100\right)$. In $(\mathrm{F})$, strong and localized immunoreactivity is mainly due to the lymphatic follicles of mucose associated lymphoid tissue.

course for many years (19). In the later stages the organs most commonly affected are lymph nodes $(60 \%)$, spleen $(50 \%)$, lungs $(43 \%)$, liver $(41 \%)$, bone $(27 \%)$, kidney $(27 \%)$, tongue and mucous membranes (19\%), heart (17\%), pancreas (17\%), and thyroid (14\%) (2). Complications within the gastrointestinal tract are rarely described in literature. Also, the GI 
Table II. A collection of reports on GI tract localization in MF.

\begin{tabular}{|c|c|c|c|}
\hline GI involvement & Location,(no of cases) & Authors & (Refs.) \\
\hline $\mathrm{P}$ & Small-bowell (1) & Camisa and Goldstein, 1981 & $(21)$ \\
\hline $\mathrm{P}$ & Esophagus (1) & Redleaf et al, 1993 & $(22)$ \\
\hline $\mathrm{S}$ & $\begin{array}{l}\text { Stomach (7) } \\
\text { Small-bowell (13) }\end{array}$ & Epstein et al, 1972 & $(23)$ \\
\hline $\mathrm{S}$ & $\begin{array}{l}\text { Oesophagus (4) } \\
\text { Stomach (4) } \\
\text { Small-bowell (6) } \\
\text { Pancreas (12) }\end{array}$ & Rappaport and Thomas, 1974 & $(24)$ \\
\hline $\mathrm{S}$ & Oesophagus (1) & Kim et al, 1990 & $(25)$ \\
\hline $\mathrm{S}$ & Small-bowell (1) & Velagapudi et al, 2011 & $(20)$ \\
\hline $\mathrm{S}$ & Biliary tract (1) & Madsen et al, 1999 & $(26)$ \\
\hline $\mathrm{S}$ & Pancreas (1) & Gottlieb et al, 2008 & $(27)$ \\
\hline $\mathrm{S}$ & Duodenal papilla (1) & Gómez-Venegas and Vargas-Rubio, 2016 & (7) \\
\hline $\mathrm{S}$ & Rectum (1) & Tan et al, 2016 & $(28)$ \\
\hline $\mathrm{S}$ & $\begin{array}{l}\text { Oral cavity (1) } \\
\text { Small-bowell (1) }\end{array}$ & Emge et al, 2016 & (29) \\
\hline $\mathrm{S}$ & Small-bowell (1) & Chen et al, 1998 & $(30)$ \\
\hline
\end{tabular}

P, primary cutaneous disease; S, spreading from cutaneous disease; MF, mycosis fungoides; GI, gastrointestinal.

involvement can be primary or spread out from cutaneous disease. The principal papers regarding this topic are listed in Table II. MF can affect, albeit rarely, every section of the GI tract from the mouth to the rectum, but also the biliary tract and pancreas. The involvement of the GI tract in most cases can run torpidly displaying non-specific symptoms. However, some reports showed abrupt and fatal complications such as small bowel obstruction (20) and massive haemorrhage from an ulcerated tumor's nodule in the stomach (5). In our case MF had an indolent course for several years until gastric involvement became apparent. The immunohistochemical study of the neoplastic lymphocyte infiltrate has provided consistent results for gastric and skin localization. In fact, in both cases the $\mathrm{T}$ lymphocyte population was represented almost exclusively by $\mathrm{CD}^{+}$elements with only rare $\mathrm{CD} 8^{+}$ lymphocytes. At that time, the disease became aggressive with nodules arising on skin plaques until, after one year of treatment, the patient died. Taking into account these data and considering the small number of cases documented in the literature, we feel like to affirm that gastric involvement in the context of MF is underestimated and then could be not so rare. Therefore, from clues we can glean that are skin manifestations getting worse, the appearance of gastric pain or other gastrointestinal symptoms it follows that MF must be carefully evaluated because the picture could be indicative of an actual systemic T-cell lymphoma and probably carrying back a poor prognosis.

\section{Acknowledgements}

Not applicable.

\section{Funding}

No funding was received.

\section{Availability of data and materials}

The datasets used and/or analyzed during the present study are available from the corresponding author on reasonable request.

\section{Author's contributions}

ES, GD and SPN conceived the current study. ES, GD, IP, AD, GS, SD, MR and NM drafted the manuscript. IP, AD, GS, SD, $\mathrm{NM}, \mathrm{MR}$ and CM reviewed and edited the manuscript. NM, MR, GS and SD collected the data. AD performed immunohistochemistry analysis. CM and IP constructed the figures. GD and ES supervised the current study. All authors read and approved the final manuscript.

\section{Ethics approval and consent to participate}

Ethical approval was obtained from of the local regional Ethics Committee ('Comitato Etico Regione Calabria, Area Centro, Azienda Ospedaliero Universitaria, Mater Domini, Catanzaro') for all procedures.

\section{Patient consent for publication}

Written informed consent was obtained from the patient at the start of observation proposing the possibility of publication in anonymous form. 


\section{Competing interests}

The authors declare that they have no competing interests.

\section{References}

1. Cerroni L: Lymphoproliferative lesions of the skin. J Clin Pathol 59: 813-826, 2006

2. Burg G: Systemic involvement in mycosis fungoides. Clin Dermatol 33: 563-571, 2015.

3. Zinzani PL, Ferreri AJM and Cerroni L: Mycosis fungoides. Crit Rev Oncol Hematol 65: 172-182, 2008.

4. Cerroni L: Mycosis fungoides-clinical and histopathologic features, differential diagnosis, and treatment. Semin Cutan Med Surg 37: 11-17, 2018.

5. Eder J, Rogojanu R, Jerney W, Erhart F, Dohnal A, Kitzwögerer M, Steiner G, Moser J and Trautinger F: Mast cells are abundant in primary cutaneous T-cell lymphomas: Results from a computer-aided quantitative immunohistological study. PLoS One 11: e0163661, 2016.

6. Scali E, Mignogna C, Di Vito A, Presta I, Camastra C, Donato G and Bottoni U: Inflammation and macrophage polarization in cutaneous melanoma: Histopathological and immunohistochemical study. Int J Immunopathol Pharmacol 29: 715-719, 2016.

7. Gómez-Venegas ÁA and Vargas-Rubio RD: Unusual involvement in mycosis fungoides: Duodenal papilla. Rev Esp Enfermedades Dig 108: 513-516, 2016

8. Furue $\mathrm{M}$ and Kadono T: New aspects of the clinicopathological features and treatment of mycosis fungoides and Sézary syndrome. J Dermatol 42: 941-944, 2015.

9. Perrotta I, Bruno L, Maltese L, Russo E, Donato A and Donato G: Immunohistochemical analysis of the ubiquitin-conjugating enzyme UbcH10 in lung cancer: A useful tool for diagnosis and therapy. J Histochem Cytochem 60: 359-365, 2012.

10. Donato G, Conforti F and Allegra E: A rare case of primary nodalhemangioendothelioma. Oncol Lett 6: 1759-1761, 2013.

11. Mignogna C, Staropoli N, Botta C, De Marco C, Rizzuto A, Morelli M, Di Cello A, Franco R, Camastra C, Presta I, et al: Aurora Kinase A expression predicts platinum-resistance and adverse outcome in high-grade serous ovarian carcinoma patients. J Ovarian Res 9: 31, 2016.

12. Whittaker S, Hoppe R and Prince HM: How I treat mycosis fungoides and Sézary syndrome. Blood 127: 3142-3153, 2016.

13. Ahmed B, Tschen JA, Cohen PR, Zaki MH, Rady PL, Tyring SK, Corringham RE and Kurzrock R: Cutaneous castleman's disease responds to anti-interleukin-6 treatment. Mol Cancer Ther 6: 2386-2390, 2007.

14. Montroni I, Sabattini E, Ramadori E, Koprivica V, Ugolini G, Locatelli F, Ghignone F, Rosati G, Taffurelli M and Pileri S: Small bowel obstruction caused by a large B-cell lymphoma in a patient with multicentric Castleman's disease: An unusual occurrence. Int J Surg Pathol 22: 434-437, 2014

15. Donato G, Ferraro G, Signorelli F, Iofrida G, Lavano A, Amorosi A, Maltese L, Perrotta I, Tripepi S, Pardatscher K and Signorelli CD: Chordoid meningioma: Case report and literature review. Ultrastruct Pathol 30: 309-314, 2006.
16. Di Vito A, Mignogna $\mathrm{C}$ and Donato G: The mysterious pathways of cardiac myxomas: A review of histogenesis, pathogenesis and pathology. Histopathology 66: 321-332, 2015.

17. Shirsat HS and Vaiphei K: Primary gastrointestinal lymphomas-A study of 81 cases from a Tertiary Healthcare Centre. Indian J Cancer 51: 290-292, 2014.

18. Peng JC, Zhong L and Ran ZH: Primary lymphomas in the gastrointestinal tract. J Dig Dis 16: 169-176, 2015.

19. Jawed SI, Myskowski PL, Horwitz S, Moskowitz A and Querfeld C: Primary cutaneous T-cell lymphoma (mycosis fungoides and Sézary syndrome): Part II. Prognosis, management, and future directions. J Am Acad Dermatol 70: 223.e1-e17, 2014.

20. Velagapudi P, Turagam M, Uzoaru I and Graham D: Small bowel obstruction due to mycosis fungoides: An unusual presentation. Am J Med Sci 341: 508-509, 2011.

21. Camisa C and Goldstein A: Mycosis fungoides: Small-bowel involvement complicated by perforation and peritonitis. Arch Dermatol 117: 234-237, 1981.

22. Redleaf MI, Moran WJ and Gruber B: Mycosis fungoides involving the cervical esophagus. Arch Otolaryngol Neck Surg 119: 690-693, 1993.

23. Epstein EH Jr, Levin DL, Croft JD Jr and Lutzner MA: Mycosis fungoides: Survival, prognostic features, response to therapy, and autopsy findings. Medicine (Baltimore) 51: 61-72, 1972.

24. Rappaport $\mathrm{H}$ and Thomas LB: Mycosis fungoides: The pathology of extracutaneous involvement. Cancer 34: 1198-1229, 1974.

25. Kim OD, Cantave I and Schlesinger PK: Esophageal involvement by cutaneous T-cell lymphoma, mycosis fungoides type: Diagnosis by endoscopic biopsy. J Clin Gastroenterol 12: 178-182, 1990 .

26. Madsen JA, Tallini G, Glusac EJ, Salem RR, Braverman I and Robert ME: Biliary tract obstruction secondary to mycosis fungoides: A case report. J Clin Gastroenterol 28: 56-60, 1999.

27. Gottlieb K, Anders K and Kaya H: Obstructive jaundice in a patient with mycosis fungoides metastatic to the pancreas. EUS findings. J Pancreas 9: 719-724, 2008.

28. Tan E, Shao H and Friedman M: Mycosis Fungoides of the Rectum: Case Report and Review of the Literature. J Gastrointest Cancer 47: 417-419, 2016.

29. Emge DA, Bassuner J, Lewis DJ and Duvic M: A rare case of mycosis fungoides in the oral cavity and small intestine complicated by perforation. Case Rep Dermatol 8: 294-302, 2016.

30. Chen KR, Tanaka M and Miyakawa S: Granulomatous mycosis fungoides with small intestinal involvement and a fatal outcome. Br J Dermatol 138: 522-525, 1998.

This work is licensed under a Creative Commons Attribution-NonCommercial-NoDerivatives 4.0 International (CC BY-NC-ND 4.0) License. 